\title{
Development of Endoscopy
}

Gastroenterology Diamond Jubilee Review

John DeWitt, MD and Jacques Van Dam, MD, PhD

Indiana University School of Medicine, Indianapolis, IN, USA and

The Keck School of Medicine of the University of Southern California, Los Angeles, CA, USA

Disclosures:

- JD: Consultant to Olympus America Inc. and Boston scientific Inc.

-JVD: No relevant disclosures

Corresponding author: Jacques Van Dam, MD, PhD

Email: jvandam@usc.edu

This is the author's manuscript of the article published in final edited form as:

DeWitt, J., \& Van Dam, J. (2018). Development of Endoscopy. Gastroenterology. https://doi.org/10.1053/j.gastro.2018.04.002 
The Diamond Anniversary of Gastroenterology provides an opportunity to look back at the key publications that led to the discovery of previously elusive digestive diseases, their pathogenesis and the development of specific targeted therapies. We have come to think of these landmark studies as being focused on the biochemical, pharmacological and molecular disciplines, and rightly so. But the journal also led the way in publishing the seminal work in the physics and engineering domains as well as the clinical trials that led to, and in many instances validated, the endoscopic tools that have become an essential part of our practice today.

\section{Flexible Fiber Optic Endoscopy, Video Endoscopy}

Flexible endoscopy wasn't introduced to our practices until the 1970s. In 1977, Bohlman et al., compared the flexible $60-\mathrm{cm}$ fiber optic sigmoidoscope with the then standard rigid sigmoidoscope and reported the superiority of the flexible instrument.(1) The results of the flexible and rigid devices were compared in over 100 patients. The use of the flexible instrument was three times more likely to detect a pathologically significant lesion (39 percent versus 13 percent). None of the subjects were given sedation or analgesia for their examination, consistent with standard practice at the time. And while the flexible instrument was inserted on average nearly three times further $(55 \mathrm{~cm}$ versus $20 \mathrm{~cm})$, more patients preferred the flexible device. The increased yield in the setting of improved patient acceptance helped open to the door for flexible endoscopy.

The theoretical pathogenesis of gastroesophageal reflux disease (GERD) was elucidated in large part with the introduction of both endoscopic and basic laboratory technologies ( $\mathrm{pH}$ measuring devices). Jacob et al., used fiber optic laryngoscopy and dual-site ambulatory $\mathrm{pH}$ recordings to assess patients with symptomatic reflux in a randomized controlled clinical trial.(2) The investigators discovered that endoscopic findings of inflammation and proximal acid exposure were significantly increased in patients with symptoms versus controls. This study demonstrated how the use of advanced technologies could help understand a disease process thus leading to the development of effective management strategies. As important as the diagnostic role of flexible endoscopy, is its potential for managing both simple and complex gastrointestinal disorders. In the 1980s, it was reported that 1500 people died annually from ingested foreign bodies of the upper digestive tract. William Webb's comprehensive review of managing such foreign bodies included the role of flexible endoscopy and a cost effectiveness analysis.(3) 
The move from fiber optic endoscopes to charge-coupled devices (CCD) also known as "electronic" or "video" endoscopes was a significant development in the evolution of endoscopy. However, it was not met with universal acceptance. The fiber optic image was considered "pure" in that there was no manipulation of the image's color or resolution. The concern regarding the introduction of the CCD was that an electronic device could introduce artifacts that would interfere with (degrade or enhance) the image in a manner that would affect the clinical outcome of an examination. In 1989, Knyrim published the results of a comprehensive bench study comparing a number of manufacturer's electronic endoscopes with fiber optic endoscopes demonstrating the comparability of images and thus helping to resolve the issue.(4)

Throughout the years, the journal established itself as an authoritative source for colorectal cancer screening guidelines. An example is the well-cited consensus guidelines by Rex et al.(5) In this particular iteration, the guidelines represent a consensus by the American Cancer Society and the US Multi-Society Task Force on Colorectal Cancer on the role of endoscopy in the surveillance of patients. The evaluation includes patients presenting with and treated for the various stages (Stage 1-Stage 4) of colon cancer. The guidelines are based in large part on the relative likelihood of synchronous and metachronous disease. Intervals for endoscopic surveillance are based on results obtained at index examination.

\section{Endoscopic retrograde cholangiopancreatography (ERCP)}

ERCP is acknowledged to be one of the major advances in flexible endoscopy over the past several decades. It has matured into an essential tool for managing biliary (obstructive jaundice, gallstones, pancreatic malignancies, biliary malignancies, etc.) and pancreatic (pancreatic malignancies, acute/chronic pancreatitis, etc.) disorders. The first successful endoscopic sphincterotomy was reported in 1974, but the editors of the journal recognized even earlier the potential of ERCP as a diagnostic and therapeutic procedure. In 1973, Ogoshi et al. published their successful experience of ERCP in 252 consecutive patients.(6) As the procedure became more broadly available and performed with more frequency, analyses of resulting radiographs became possible. Misra et al. analyzed 259 ERCPs including 102 normal examinations (control group) and compared them with patients with gallstone disease and cancer in an effort to determine an association between ductal anatomy and significant pancreaticobiliary disease.(7) Their observations suggested a close association between the anatomy of the distal common bile duct and the length of the so-called "common channel" as contributing factors. Similarly, Venu et al. reviewed their extensive experience in ERCP to assess its potential for evaluating 
rare congenital abnormalities of the biliary tree such as choledochocele.(8) Their observations demonstrated the superiority of ERCP over existing imaging techniques.

Not all landmark ERCP studies published in the journal are from the bygone era. Our current practice has seen the introduction of such innovative endoscopic technologies as the self-expandable metal stent (SEMS). SEMS are placed during ERCP for palliation of extrahepatic bile duct obstruction and come in a covered and uncovered configuration. (For a discussion of EUS-associated SEMS indications, see below). Although SEMS remain patent longer than their predecessor plastic stents, they are more expensive raising the question of cost effectiveness. In 2015, Walter et al. published a comprehensive, multicenter (18 medical centers) five-year study $(2008-2013)$ to address this clinically relevant question.(9) Their conclusions showed that the after one year, the cost difference between the endoscopic use of plastic stents and the initially more expensive SEMS did not differ significantly.

Post-ERCP pancreatitis is one of the dreaded complications of ERCP. Indomethacin suppositories were introduced to interventional endoscopists as a method to overcome/mitigate the incidence of postERCP pancreatitis in their patients. But it was Northway et al., in 1980 that demonstrated the protective effect of indomethacin in preventing the inflammatory condition radiation esophagitis in the opossum. (10) In their study, 25 animals were evaluated by fiber optic endoscopy before irradiation. The protective effect of indomethacin was hypothesized to be caused by the blockade of prostaglandin synthesis.

The well-publicized recent outbreaks of endocope-associated transmission of infection with the endoscope as vector ("elevator-equipped" endoscopes, duodenoscopes, echoendoscopes) are currently the subject of litigation and society guideline revision. But the possibility of endoscope transmission of infection was published in the journal as early as the 1970s and 1980s. In 1974, Greene et al. reported that a small number of immunocompromised cancer patients undergoing flexible fiber optic esophagoscopy died of Pseudomonas aeruginosa septicemia shortly after their procedure.(11) Analysis of the Pseudomonas infectious serotypes showed that none were recovered from the patients prior to the endoscopic procedure but were widespread with contamination of the endoscope. In 1982, Gerding et al. combined the resources of the infectious disease section and gastroenterology section at the Minneapolis Veteran's Affairs Medical Center to publish a comprehensive study on cleaning and disinfection of flexible fiber optic endoscopes.(12) The data generated contributed to the creation of 
reprocessing guidelines. The recognition of the problem and the publication of a thoughtful scientific approach to resolving it are an example of the journal's role in endoscopic matters.

\section{Endoscopic Ultrasound}

With the advent of improved imaging for fiberoptic endoscopy, attention was turned to imaging of the gastrointestinal wall and structures outside the lumen. By the late 1970s, there was robust clinical experience with echocardiography and even probe based transrectal ultrasound imaging of the colon wall and adjacent pelvic structures. However, researchers realized that it was essential to overcome intervening bowel wall gas in order to utilize ultrasound to visualize structures such as the body and tail of the pancreas. Therefore, an ultrasonic probe was developed to fit to the tip of a gastroscope to overcome these limitations. Initial experiments with this ultrasonic endoscope in dogs confirmed that real-time transesophageal and transgastric imaging of the mediastinum and upper abdominal structures could be obtained with $<1 \mathrm{~mm}$ resolution. In 1982, Dimagno et al. (13) described one of first experiments of EUS in humans. In this study, 32 EUS exams were performed in 15 healthy patients and 12 patients with pancreatic or gastrointestinal disorders. The researchers concluded that EUS was safe, could visualize normal and diseased abdominal organs and differentiate mucosal from intramural disease. This and other pioneering research led to more published descriptions and utilization of EUS for intramural and extramural disease.

While demonstration of extramural structures is important, it is critical to understand the anatomical correlates of intramural imaging. EUS imaging of the gastrointestinal wall at $7.5 \mathrm{MHz}$ usually produces a 5-layer structure that is alternating hyperechoic (bright), hypoechoic (dark), hyperechoic, hypoechoic and hyperechoic. Kimmey et al. (14) compared ultrasound imaging with histologic sections of resected and postmortem specimens from normal and diseased gastrointestinal wall tissue. This study found that this 5-layer structure corresponds to the: 1) superficial mucosa; 2) deep mucosa; 3) submucosa and muscularis propria interface; 4), muscularis propria and; 5) serosa with subserosal fat, respectively. Understanding these histologic correlates provided the foundation for future endosonographers to discern the layer of origin or invasion of intramural subepithelial lesions.

Due to its ability to image the entire pancreas, endoscopists reported in the early 1990s that radial EUS imaging (perpendicular to the long axis of the endoscope) could identify small pancreatic neoplasms such as endocrine tumors missed by other imaging studies such as transcutaneous ultrasound and CT 
scan (15). Rosch et al. (16) also reported that EUS was superior to conventional ultrasound, CT and angiography for the local staging and evaluation of portal vein invasion in surgically resectable patients with pancreatic and ampullary cancer and advocated its use to decrease the rate of unnecessary operations. With Improved CT scan technology (thin slices and precisely timed imaging after contrast administration), it proved equivalent to EUS for identification of resectability for pancreatic cancer but still misses small tumors that can be identified and biopsied by EUS (17).

In the early 1990s, the development of linear endosonography permitted imaging ultrasound imaging sagittally relative to the endoscope shaft and thus visualization of accessories passed passage through the working channel of the endoscope. The first EUS-guided fine needle aspiration (EUS-FNA) was published in 1992 (18) and transformed EUS from purely a diagnostic imaging technique to a potentially therapeutic tool. Soon after these reports, additional techniques utilizing EUS were reported such as celiac plexus block and neurolysis, pseudocyst drainage, cholangiography and pancreatography and bile duct drainage. As with any new technique, there was some skepticism about whether endoscopic therapy could replace or become an acceptable alternative to established radiologic or surgical therapies. However, studies soon emerged that would challenge existing paradigms. In a prospective randomized trial, Varadarajulu et al (19). reported that cystgastrostomy drainage of pancreatic pseudocysts by EUS using two plastic stents $(n=20)$ and surgical cystgastrostomy $(n=20)$ produced similar treatment success, complications and need for reintervention. However, the endoscopic approached lowered cost, improved the physical and mental health of patients and shortened the duration of hospitalization compared to surgical arm. For patients with acute cholecystitis who failed to respond to medical therapy and could not undergo cholecystectomy, Jang et al (20). randomized patients to EUSguided placement of a $5 \mathrm{Fr}$ nasobiliary drainage $(n=30)$ or percutaneous transhepatic gallbladder drainage (PTGBD, $n=29$ ). These authors found that EUS guided gallbladder drainage and PTGBD produced comparable clinical efficacy, technical feasibility and safety. These studies helped to established drainage by therapeutic EUS as acceptable alternatives to traditional techniques however they utilized plastic stents to facilitate drainage. The recent introduction of lumen apposing metal stents (LAMS) placed under EUS guidance has decreased the number of steps required and improved the safety and stability of endoscopic transmural drainage compared to plastic stents. EUS-guided placement of LAMS are now routinely utilized for transmural gallbladder drainage, pseudocyst drainage and access for translumenal necrosectomy, hepatogastrostomy and choledochoduodenostomy. 


\section{Natural orifice translumenal endoscopic surgery (NOTES)}

NOTES can be performed either within or outside the gastrointestinal tract. Within the submucosal space of the gastrointestinal tract it is used to remove subepithelial tumors (submucosal tunneling with endoscopic resection, STER) or to provide a conduit for therapy (i.e. per-oral endoscopic myotomy, POEM for achalasia). NOTES can also provide endoscopic access to adjacent or distant organs or facilitate full thickness removal of the regions of the gastrointestinal tract (EFTR). Transluminal drainage of pseudocysts and 'gastrostomy without laparotomy' (21) were the first true NOTES procedures performed in the modern era. Kalloo et al. (22) performed the first transgastric peritoneoscopy in a porcine model and ushered in excitement for this novel field. Since then, NOTES research has been conducted in several areas: 1) local surgery without puncture of an organ (direct-target NOTES) and intentional violation of an organ to operate in a remote location (distant-target NOTES); 2) which orifice (anus, vagina, mouth) to enter to perform surgery; 3 ) whether NOTES should be performed in a pure form (without external assistance) or hybrid form (utilizing laparoscopic assistance); 4) novel instrumentation to facilitate the procedure; 5) safety and training for NOTES by gastroenterologists or surgeons; 6) quality of life and costs of the procedure. Currently, common NOTES procedures performed clinically include the direct-target procedures POEM, STER, and the hybrid NOTES procedure transanal total mesorectal excision (trans-TME). Distant NOTES include transluminal necrosectomy and transgastric cholecystectomy. Innovation in this field is expanding rapidly and expectations must be tempered as research is performed to determine the safety, outcomes, patient preferences, quality of life, training required and costs of these procedures. 


\section{References:}

1. Bohlman, T.W., Katon, R.M., Lipshutz, G.R., McCool, M.F., Smith, F.W., Melnyk, C.S. Fiberoptic Pansigmoidoscopy: An evaluation and comparison with rigid sigmoidoscopy (1977) Gastroenterology, 72 (4), pp. 644-649. Cited 91

2. Jacob, P., Kahrilas, P.J., Herzon, G. Proximal esophageal pH-metry in patients with 'reflux laryngitis' (1991) Gastroenterology, 100 (2), pp. 305-310. Cited 269

3. Webb, W.A. Management of foreign bodies of the upper gastrointestinal tract (1988) Gastroenterology, 94 (1), pp. 204-216. Cited 205

4. Knyrim, K., Seidlitz, H., Vakil, N., Hagenmuller, F., Classen, M. Optical Performance of Electronic Imaging Systems for the Colon (1989) Gastroenterology, 96 (2), pp. 776-782. Cited 15

5. Rex, D.K., Kahi, C.J., Levin, B., Smith, R.A., Bond, J.H., Brooks, D., Burt, R.W., Byers, T., Fletcher, R.H., Hyman, N., Johnson, D., Kirk, L., Lieberman, D.A., Levin, T.R., O'Brien, M.J., Simmang, C., Thorson, A.G., Winawer, S.J. Guidelines for Colonoscopy Surveillance After Cancer Resection: A Consensus Update by the American Cancer Society and the US Multi-Society Task Force on Colorectal Cancer (2006) Gastroenterology, 130 (6), pp. 1865-1871. Cited 220

6. Ogoshi, K., Niwa, M., Hara, Y., Nebel, O.T. Endoscopic Pancreatocholangiography in the Evaluation of Pancreatic and Biliary Disease (1973) Gastroenterology, 64 (2), pp. 210-216. Cited 81

7. Misra, S.P., Gulati, P., Thorat, V.K., Vij, J.C., Anand, B.S. Pancreaticobiliary Ductal Union in Biliary Diseases: An Endoscopic Retrograde Cholangiopancreatographic Study (1989) Gastroenterology, 96 (2), pp. 907-912. Cited 59 times.

8. Venu, R.P., Geenen, J.E., Hogan, W.J., Dodds, W.J., Wilson, S.W., Stewart, E.T., Soergel, K.H. Role of Endoscopic Retrograde Cholangiopancreatography in the Diagnosis and Treatment of Choledochocele (1984) Gastroenterology, 87 (5), pp. 1144-1149. Cited 91 times.

9. Walter, D., Van Boeckel, P.G.A., Groenen, M.J., Weusten, B.L.A.M., Witteman, B.J., Tan, G., Brink, M.A., Nicolai, J., Tan, A.C., Alderliesten, J., Venneman, N.G., Laleman, W., Jansen, J.M., Bodelier, A., Wolters, F.L., Van Der Waaij, L.A., Breumelhof, R., Peters, F.T.M., Scheffer, R.C.H., Leenders, M., Hirdes, M.M.C., Steyerberg, E.W., Vleggaar, F.P., Siersema, P.D. Cost Efficacy of Metal Stents for Palliation of Extrahepatic Bile Duct Obstruction in a Randomized Controlled Trial (2015) Gastroenterology, 149 (1), art. no. 59673, pp. 130-138. Cited 19 times.

10. Northway, M.G., Libshitz, H.I., Osborne, B.M., Feldman, M.S., Mamel, J.J., West, J.H., Szwarc, I.A. Radiation esophagitis in the opossum: Radioprotection with indomethacin1 1 The indomethacin used in these studies was supplied by Dr. Clement A. Stone, Merck, Sharpe and Dohme, and the 16, 16-dimethylprostaglandin E2 was supplied by Dr. John Pike, The Upjohn Company. (1980) Gastroenterology, 78 (5 PART 1), pp. 883-892. Cited 82

11. Greene, W.H., Moody, M., Hartley, R., Effman, E., Aisner, J., Young, V.M., Wiernik, R.H. Esophagoscopy as a source of Pseudomonas aeruginosa sepsis in patients with acute leukemia: the need for sterilization of endoscopes (1974) Gastroenterology, 67 (5), pp. 912-919. Cited 93 
12. Gerding, D.N., Peterson, L.R., Vennes, J.A. Cleaning and Disinfection of Fiberoptic Endoscopes: Evaluation of Glutaraldehyde Exposure Time and Forced-Air Drying (1982) Gastroenterology, 83 (3), pp. 613-618. Cited 46

13. Dimagno EP, Regan PT, Clain JE, James EM, Buxton JL. Human Endoscopic Ultrasonography. Gastroenterology 1982; 83:824-829

14. Kimmey MB, Martin RW, Haggitt RC, Wang KY, Franklin DW, Silverstein FE. Histologic correlates of gastrointestinal ultrasound images. Gastroenterology 1989;96: 433-4.

15. Rösch T, Lightdale CJ, Botet JF, Boyce GA, Sivak MV Jr, Yasuda K, Heyder N, Palazzo L, Dancygier $\mathrm{H}$, Schusdziarra $\mathrm{V}$, et al. Localization of pancreatic endocrine tumors by endoscopic ultrasonography. N Engl J Med 1992;326:1721-6.

16. Rösch T, Braig C, Gain T, Feuerbach S, Siewert JR, Schusdziarra V, Classen M. Staging of pancreatic and ampullary carcinoma by endoscopic ultrasonography. Comparison with conventional sonography, computed tomography, and angiography. Gastroenterology 1992; 102:188-99

17. DeWitt J, Devereaux B, Chriswell M, McGreevy K, Howard T, Imperiale TF. Comparison of endoscopic ultrasonography and multidetector computed tomography for detecting and staging pancreatic cancer. Ann Intern Med 2004;141:753-63.

18. Vilman P, Jacobsen GK Henriksen FW et al. Endoscopic ultrasonography with fine needle aspiration biopsy in pancreatic disease. Gastrointest Endosc 1992; 38:172-3.

19. Varadarajulu S, Bang JY, Sutton BS, Trevino JM, Christein JD, Wilcox CM. Equal efficacy of endoscopic and surgical cystogastrostomy for pancreatic pseudocyst drainage in a randomized trial. Gastroenterology 2013;145:583-90.

20. Jang JW, Lee SS, Song TJ, Hyun YS, Park DH, Seo DW et al. Endoscopic ultrasound-guided transmural and percutaneous transhepatic gallbladder drainageare comparable for acute cholecystitis. Gastroenterology 2012; 142: 805-811

21. Gauderer MW, Ponsky JL< Izant RJ Jr. Gastrostomy without laparotomy: a percutaneous endoscopic technique. J Pediatr Surg 1980; 15: 872-875.

22. Kalloo AN, Singh VK, Jagannath SB, Niiyama H, Hill SL, Vaughn CA et al. Flexible transgastric peritoneoscopy: a novel approach to diagnostic and therapeutic interventions in the peritoneal cavity. Gastrointest Endosc 2004; 60:114-117. 